\title{
Sensibilidad ciudadana: sentidos y prácticas en jóvenes universitarios*
}

\section{Citizen sensitivity: senses and practices among young university students}

\author{
Recibido: 29 de enero de 2016/Aceptado: 27 de septiembre de 2016 \\ http://doi.org/10.17081/psico.20.37.2423
}

Palabras clave:

Jóvenes universitarios, Sensibilidad ciudadana, Diversidad, Respeto, Normas.
Key words:

University Students,

Citizen sensitivity,

Diversity, Respect, Norms.

\author{
Ana María Arias Cardona ${ }^{1}$, Jeisy Andrea Mazo Peña ${ }^{2}$ \\ Corporación Universitaria Lasallista, Colombia
}

\begin{abstract}
Resumen
Este artículo realza la pregunta por la sensibilidad ciudadana. Con el objetivo de comprender esta cualidad en jóvenes universitarios, se llevó a cabo un diseño mixto de investigación, con un método de estudio de caso y tres técnicas de construcción de datos: cuestionario, grupo focal y fotolenguaje. Se hallaron diferentes resultados, en los que prevalece la voz de los jóvenes en relación con tres categorías: el equilibrio entre deberes y responsabilidades, el respeto a la diferencia y las relaciones de inclusión. Respecto a la primera categoría, los participantes, pese a expresar reflexiones conscientes sobre la importancia de las normas, respuesta dada por el 58,46\% de ellos, suelen priorizar sus derechos y desdibujar sus responsabilidades. Sobre la segunda y la tercera categoría (el respeto a la diferencia y las relaciones de inclusión), llama la atención el positivo significado que les asignan y la intención de valorarlo, aspectos que refieren el 45,69 \% y el 53,85\% de los jóvenes, respectivamente. Asunto que no necesariamente coincide con sus prácticas en el día a día, donde se han naturalizado acciones de discriminación y exclusión.
\end{abstract}

\begin{abstract}
This article highlights the questioning for citizen sensitivity. Aiming to understand the citizen sensitivity in university students, a mixed research model was conducted with the Case Study Method and three techniques of data construction: questionnaire, focus group and photo language. Different results were found in which the voice of the young prevails in relation to three categories: the balance between rights and responsibilities, the respect for the difference and inclusive relationships. Referring to the first category, the participants, despite of expressing their conscious reflections about the importance of norms-answer given by $58,46 \%$ of them- tend to prioritize their own rights and distort their responsibilities. As for the second and third category (respect for the difference and inclusive relationships), it is worth noting the positive meaning that the participants assign to it and the intention to cherish It. Such aspects were recognized by $45,69 \%$ and $53,85 \%$ of young people respectively. This matter does not necessarily matches with their day-to-day practices, where discrimination and exclusion practices have been rather interiorized.
\end{abstract}

\section{(c) (i) $\Theta$}

Referencia de este artículo (APA):

Arias, A. \& Mazo, J. (2017). Sensibilidad ciudadana: sentidos y prácticas en jóvenes universitarios. Psicogente, 20(37), 135-145.

http://doi.org/10.17081/psico.20.37.2423

\footnotetext{
Este artículo da cuenta del resultado de la prueba piloto y del trabajo de campo preliminar de la docente Ana María Arias Cardona realizado en el marco de su proyecto de tesis doctoral "Relaciones sociales en la universidad: poder, conflicto y pluralidad entre jóvenes", en el periodo 2012-2016. Proyecto aprobado por el Sistema de Investigación Lasallista -SIL-, de la Corporación Universitaria Lasallista.

1. Doctora en Ciencias Sociales: Niñez y Juventud. Docente tiempo parcial Facultad de Ciencias Sociales y Educación. Corporación Universitaria Lasallista. Email: anamaria2468@gmail.com; anarias@lasallistadocentes.edu.co http://orcid.org/0000-00202-448-7311

2. Estudiante de octavo semestre Psicología de la Corporación Universitaria Lasallista. Joven Investigadora, Auxiliar de investigación. Email: je.sy94@hotmail.com http://orcid.org/0000-0001-5544-1653
} 


\section{Introducción}

La pluralidad humana, básica condición tanto de la acción como del discurso, tiene el doble carácter de igualdad y distinción. Si los hombres no fueran iguales, no podrían entenderse ni planear y prever para el futuro las necesidades de los que llegarán después. Si los hombres no fueran distintos, es decir, cada ser humano diferenciado de cualquier otro que exista, no necesitarían el discurso y la acción para entenderse.

Signos y sonidos bastarian para comunicar las necesidades inmediatas e idénticas.

Arendt (1993)

La socialización humana se caracteriza por los sentimientos de pluralidad, unión y convivencia. Diariamente, las personas realizan cortas interacciones que terminan convirtiéndose en rutinas, pero esto no significa que carezcan de relevancia, pues, significativamente descansan sobre una fuerte organización cultural. La funcionalidad de la interacción no se limita a la organización social, pues se transforma y se constituye en un elemento base para la formación de tradiciones, de la opinión pública y de la construcción de la sociabilidad (Rodríguez \& Rodríguez, 2013).

De acuerdo con esto, en los procesos de socialización se determinan diferentes estados de relaciones que involucran "de manera directa, implícita o explícita, a todas las personas que hacen parte del mundo social y cultural, en relaciones fundamentales que median la transmisión, deconstrucción y reconstrucción del conocimiento cultural" (Alvarado, Arias, Gómez \& Pineda, 2013, p.2).

Dichas relaciones se configuran mediante normativas, reglamentos y cualidades que integran la capacidad de los individuos, como ciudadanos, para trabajar a la par, a fin de generar impactos y compromisos sociales.
Por ello, para hacer referencia a aquellas condiciones y formas de un ciudadano de crear identidad, se recurre a la sensibilidad ciudadana en forma paralela a una posición activa de respeto por las diferentes identidades y la capacidad de trabajar simultáneamente con ellas, pues esto es signo de la responsabilidad que adquiere con el cuidado y respeto de los derechos humanos, su apreciación por las instituciones democráticas y la defensa de la sociedad con sentido de humanidad (Gómez \& Ruiz, 2011).

En este artículo, la sensibilidad ciudadana se analiza a través de tres subcategorías: primero, el equilibrio entre derechos y responsabilidades; segundo, el respeto a la diferencia y; tercero, las relaciones de inclusión. Tal como se resume en la Figura 1.

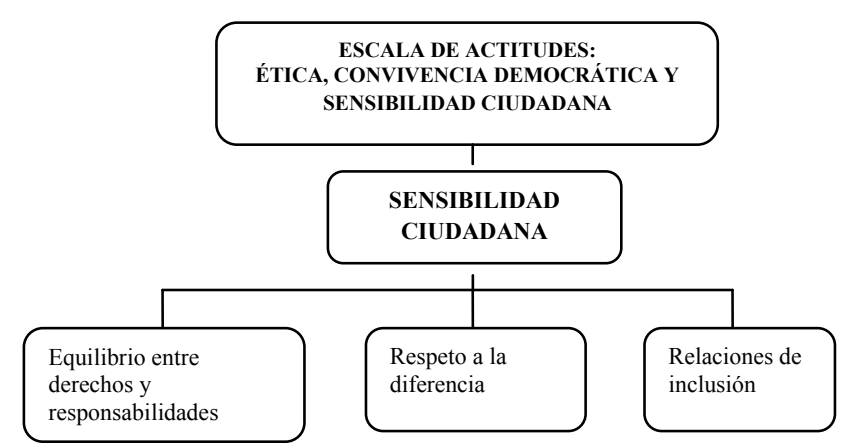

Figura 1. Escala de actitudes: ética, convivencia democrática y sensibilidad ciudadana

La primera categoría, equilibrio entre derechos y responsabilidades, implica concordancia en términos sociales y jurídicos, y se expresa en la afirmación del valor de la ley y la norma, encaminado a la vida en común, siempre y cuando no se violente la dignidad humana. También se expresa en la exigencia de su cumplimiento a todos los organismos de la comunidad, incluyendo su acceso pertinente para su amparo. Al respecto, la consideración de los derechos humanos como sistema que sobrepasa las legislaciones de los Estados es lo que 
define a una sociedad cuyo régimen político es verdaderamente democrático, pues articula la búsqueda de la dignidad humana (Gómez \& Ruiz, 2011) y justifica que "el ejercicio de la democracia, en este sentido, requiera de ciudadanos dispuestos a exigir y autoexigirse respeto por la dignidad humana y reciprocidad en las acciones con contenido moral" (Gómez \& Ruiz, 2011, p.5).

En esta investigación fue común escuchar situaciones donde los estudiantes privilegian el discurso sobre sus propios derechos, por ejemplo, en situaciones difíciles con los docentes. En casos como estos, pocas veces asumen su propia responsabilidad subjetiva o se preguntan por aquello de sus actos $\mathrm{u}$ omisiones que estuvieron en juego en la situación.

Este equilibrio entre derechos y responsabilidades se podría asimilar "como un elemento esencial para el establecimiento de intercambio social, la existencia (tanto interna como externa) de normas que organizan y estructuran esa interacción" (Nateras, 2003, p.55). Es decir, que en el quehacer de lo democrático cobra valor la actuación del ciudadano como ejecutor y beneficiario de los derechos tangibles.

Lo anterior se evidencia en los jóvenes en lo relativo a algunos comportamientos básicos, como las elecciones de los representantes o los procesos de toma de decisiones a nivel grupal, situaciones en las que reconocen su rol activo dentro de la comunidad como hacedores y responsables del mantenimiento de ese quehacer democrático. Asimismo, ello se manifiesta en las exigencias a las demás instancias sociales del mismo compromiso adquirido.

La segunda categoría, respeto a la diferencia, se define como "consideración y aceptación de la diversidad cultural, racial, socioeconómica y generacional. También podemos entender el respeto a la diferencia como las valoraciones favorables que hacemos de las necesidades y sentidos de personas de otras comunidades, así como de sus tradiciones" (Gómez \& Ruíz, 2011, p.5). Cabe señalar en este sentido, que en un sistema cooperativo, que promulga el trabajo por el bien común, es el otro quien se convierte en el aliado permanente para la consolidación de las diferentes construcciones sociales que ameritan la diversidad como condición indispensable para el desarrollo.

La diversidad da cuenta de una identidad particular que se edifica a través de la colectividad, pero que también permite ser diferenciada, es decir:

La identidad se construye al interior de las relaciones que las personas establecen con otros, con otras y consigo mismos y mismas, esto en tanto las relaciones propician espacio-tiempos en los que se dice que las maneras de pensar y habitar el mundo se desplazan, intervienen sobre las otras y se modifican; poniendo en diálogo formas de ver, sentir, construir y transformar la realidad (Alvarado, Santacoloma \& Loaiza, 2011, p.141).

Estas diferencias, que se han de poner en diálogo, dan significado al sistema social, pues ameritan la puesta en escena de categorías particulares como la pertenencia a una etnia, una clase social, económica, etc. Y aun otras menos concretas, tales como ideologías, creencias y demás, para así dar cuenta de las peculiaridades individuales y de las dinámicas sociales que se forman y transforman en el seno de dicho sistema.

Es importante mencionar la existencia de la diversidad en medidas diferentes con respecto a las dos 
universidades donde se realizó la prueba piloto (la Universidad de Antioquia, de carácter público, y la Corporación Universitaria Lasallista, de carácter privado), pues, en la universidad pública hay mayor pluralidad, por cuestiones demográficas y sociales, mientras que en la universidad privada se evidencian unas características más homogéneas.

A la tercera categoría, relaciones de inclusión, "las entendemos desde una perspectiva social y política que asume que el respeto, la dignidad y los derechos del otro, no pueden ser descalificados o violentados por acciones o normas que eventualmente los afecten" (Gómez \& Ruiz, 2011, p.5).

Los jóvenes participantes en este proyecto aseveran que ante las diferencias de otra persona es importante la prevalencia del respeto, siempre y cuando el otro cumpla también su parte. Expresan, además, que cuando saben de grupos o personas que vulneren los derechos del otro por ser este diferente, tienden a excluirlos y a manifestar sus inconformidades con respecto a sus acciones.

De otro lado, estos elementos relacionados con la sensibilidad ciudadana, se configuran, tal como lo propone Alvarado, Santacoloma \& Loaiza (2011), en unas tramas relacionales, que se pueden explicar a través de la perspectiva sistémica. En este sentido es en la interacción entre lafamilia, la escuela, el barrio y demás, desde donde se da cuenta de la funcionalidad de un todo. "Desde esta perspectiva, el comportamiento social depende de la interacción entre los miembros de los diversos sistemas y de sus intercambios con otros sistemas, constituyéndose desde la interacción propiedades emergentes, que trascienden la suma de los miembros del sistema inicial” (Boscolo, Cecchin, Hoffman \& Penn,
2003, como se citó en Alvarado, Santacoloma \& Loaiza, 2011, p.4).

En este marco, las instituciones educativas son reflejo del macrosistema en el que se encuentran inmersas; pues en ellas se reproducen las prácticas y enseñanzas que el tipo de sociedad pretende desarrollar, y que se consolida mediante la forma de educar a las nuevas generaciones. "En tal sentido, toda educación, con mayor razón la educación para la comprensión y sensibilidad ciudadana, es necesariamente un acto moral y político" (Secretaría de Educación Distrital de Santafé de Bogotá, 2000, p.5) y ello compete también a las Instituciones de Educación Superior (IES), como es el caso de aquella en la que se desarrolló esta investigación.

En efecto, las instituciones educativas "dan información sobre el funcionamiento del sistema, los derechos, etcétera; siendo un espacio distinto para experimentar relaciones de poder y autoridad; y también pretende promover la participación” (Arias \& Alvarado, 2015, p.35). Y, como propone Castillo (2011), ellas juegan un papel decisivo en la construcción de identidad del sujeto joven, con sus intenciones de originar un sujeto funcional, tolerante frente a la diferencia y capacidad de construcción social.

Sin embargo, en nuestro contexto particular, "dicha socialización se complejiza dada la situación colombiana que da cuenta de la degradación del vínculo social, manifestada en múltiples violencias que han sido naturalizadas y en la agudización del conflicto armado" (Arias \& Alvarado, 2015, p.35). Así, como afirman Arias, Arias, Jaramillo, Restrepo y Ruiz (2013), al acercarse a las realidades juveniles se observan las frecuentes fragmentaciones e inestabilidades que presentan las relaciones de los jóvenes, articuladas bajo rivalidades y 
violencia simbólica, que se evidencian en las dificultades para trabajar en grupo y afrontar los conflictos cotidianos de una manera constructiva. Este asunto evidencia en lo micro las tensiones y complejidades de lo macro.

Este artículo constituye un acercamiento a las instituciones educativas, en especial a las universitarias, primero como manifestaciones de los diferentes acontecimientos sociales, que pueden comprenderse a través de los relatos, las expresiones y vivencias de los jóvenes que allí estudian; y segundo, como campo de estudio con posibilidades de análisis estadísticos sobre estos mismos acontecimientos sociales, a partir de una mirada racional sobre la sensibilización ciudadana y sus componentes.

\section{Método}

\section{Diseño}

Nuestra investigación fue de diseño mixto: Se aplicó con miras a la ampliación de un fenómeno que pareciera ser únicamente cualitativo por su condición social y subjetiva, pero cuyo conocimiento también es posible a través de técnicas cuantitativas. Se propone, por tanto, la complementación de dichos enfoques para insistir a fin de obtener una perspectiva más amplia y profunda del fenómeno, producir datos más ricos y variados mediante las múltiples observaciones, así como indagaciones más dinámicas, entre otras aproximaciones a las cualidades del uso de este tipo de diseño investigativo (Hernández, Fernández \& Baptista, 2010).

El método fue el estudio de casos (realizado en las dos universidades ya referidas), que Martínez (2011) propone como un "estudio cuyo objetivo es documentar una experiencia o evento en profundidad o entender un fenómeno desde la perspectiva de quienes lo vivieron; no persigue ninguna clase de generalización" (p.31); y las técnicas que se utilizaron fueron: el fotolenguaje, el cuestionario y el grupo focal.

El fotolenguaje, como técnica interactiva, pretende "evocar los espacios en donde transcurren los procesos, textualizando situaciones y experiencias de los sujetos relacionadas a los usos del espacio, a sus actores, a sus reglas y a sus temporalidades" (García, González, Quiroz \& Velásquez, 2002, p.75). Para su concretización, se les presentó a los estudiantes las imágenes registradas en la Tabla 1.

Tabla 1. Fotolenguaje

\begin{tabular}{lll}
\hline \multicolumn{1}{c}{ Tema } & \multicolumn{1}{c}{ Tipo de Imagen } & \multicolumn{1}{c}{ Objetivo } \\
\hline $\begin{array}{l}\text { Diversidades } \\
\text { étnicas }\end{array}$ & $\begin{array}{l}\text { Personas de diferentes } \\
\text { culturas que se recono- } \\
\text { cen por su vestimenta y } \\
\text { rasgos físicos }\end{array}$ & $\begin{array}{l}\text { Se busca comprender el } \\
\text { resper la diferencia, la } \\
\text { participación política y la ca- } \\
\text { pacidad de deliberación }\end{array}$ \\
\hline \multirow{2}{*}{$\begin{array}{l}\text { Acciones } \\
\text { juveniles }\end{array}$} & Grafiti y daño público & $\begin{array}{l}\text { Dirigido a la perspectiva } \\
\text { sobre sentido de justicia, } \\
\text { conocimiento y respeto por } \\
\text { las normas y resolución de } \\
\text { conflictos }\end{array}$ \\
\hline Orientación & $\begin{array}{l}\text { Dos hombres y dos } \\
\text { mujeres besándose, un } \\
\text { grupo de hombres y una } \\
\text { mujer, un grupo de mu- }\end{array}$ & $\begin{array}{l}\text { Orientado a relaciones de } \\
\text { inclusión y respeto por la } \\
\text { diferencia }\end{array}$ \\
\hline jeres y un hombre & $\begin{array}{l}\text { Dos equipos de fútbol, } \\
\text { niño mutilado por una } \\
\text { mina, etc. }\end{array}$ & $\begin{array}{l}\text { Encaminada a la compren- } \\
\text { sión sobre la convivencia }\end{array}$ \\
\hline convivencia &
\end{tabular}

Con base en las imágenes, se propició la construcción de una historia ficticia, incitando la expresión libre y espontánea a través de la imaginación, en tanto no cabe duda que la creatividad en estos casos no es una simple herramienta, sino que representa una acción particular del sujeto grabada por sus sentidos subjetivos, conformada por lo cognitivo y lo afectivo (Mitjáns, 2013). 
La segunda técnica aplicada fue el cuestionario, concretamente el diseñado por la Fundación CINDE y denominado:"Escala de actitudes: ética, convivencia democrática y sensibilidad ciudadana" (Gómez \& Ruiz, 2011). Se solicitó a la Dirección del CINDE la autorización para el uso y modificación de la escala para su implementación y modificación.

Este cuestionario evalúa tres tipos actitudinales diferentes: ética, convivencia democrática y sensibilidad ciudadana, que sin embargo se conectan teórica y experiencialmente. Cada escala se evalúa de acuerdo con los ítems que la conforman. Por ejemplo, el equilibrio entre derechos y deberes se valora a través de ítems específicos en la escala de actitudes para la dimensión de sensibilidad ciudadana. En conclusión, para cada dimensión, se diseñó una escala que evalúa su totalidad y cada uno de sus criterios.

La tercera técnica utilizada fue el grupo focal. Como técnica de construcción de datos, este consiste en una entrevista grupal semiestructurada, guiada por diferentes preguntas previamente diseñadas que buscan indagar sobre experiencias, creencias, actitudes o emociones en relación a una temática particular (Hernández, Fernández \& Baptista, 2010).

Respecto a los lineamientos éticos, se consideraron el anonimato, el consentimiento informado, el retorno social de la información y las relaciones de reciprocidad.

\section{Participantes}

Esta investigación se realizó con diferentes estudiantes de la Corporación Universitaria Lasallista (en el municipio de Caldas, Antioquia) y la Universidad de Antioquia (en Medellín). Los sujetos fueron selecciona- dos por medio de un muestreo estratificado, en el que participaron 65 jóvenes: 32 mujeres y 33 hombres entre 16 y 18 años, pertenecientes a estratos socioeconómicos entre 3 y 4 . Fueron estudiantes del primer semestre de distintos pregrados, tal como se evidencia en la Figura 2.

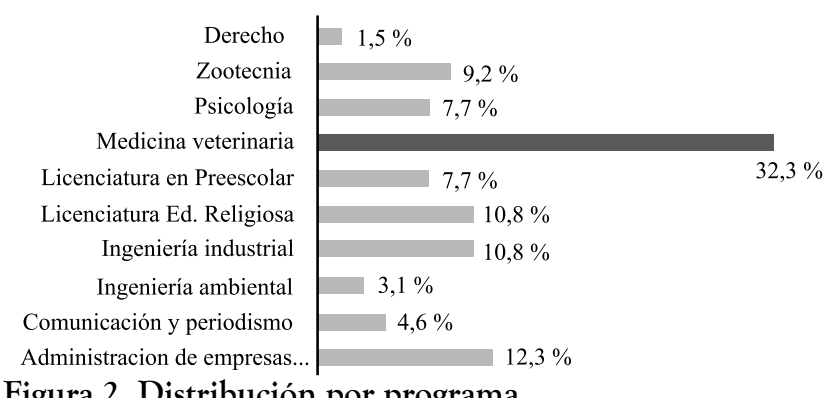

Figura 2. Distribución por programa

Finalmente, cabe anotar que el procesamiento de la información se realizó con el software SPSS y se elaboraron gráficos bajo la metáfora del semáforo, en la que el rojo corresponde a nivel bajo, el amarillo es nivel medio y verde es nivel alto.

Para el análisis de los grupos focales y el fotolenguaje, los cuales fueron grabados con autorización de los participantes y posteriormente transcritos, se implementó la técnica de análisis de contenido, a través de la codificación por colores y el uso de una matriz categorial, que se ejemplifica en la Tabla 2.

Tabla 2. Análisis de contenido: matriz categorial

\begin{tabular}{|c|c|c|c|}
\hline Categoría & Subcategoría & Testimonios & Observaciones \\
\hline $\begin{array}{l}\text { Sensibilidad } \\
\text { ciudadana }\end{array}$ & $\begin{array}{l}\text { Respeto a la } \\
\text { diferencia }\end{array}$ & $\begin{array}{l}\text { S2: "Porque a uno } \\
\text { le venden la concep- } \\
\text { ción de un cuerpo } \\
\text { perfecto, de una } \\
\text { línea perfecta, en- } \\
\text { tonces cuando ven a } \\
\text { alguien que se sale de } \\
\text { eso, todo el mundo } \\
\text { empieza a criticarlo, } \\
\text { a mirarlo feo, a ex- } \\
\text { cluirlo por eso" }\end{array}$ & $\begin{array}{l}\text { Se evidencia lo ex- } \\
\text { puesto por Alvara- } \\
\text { do, Santacoloma y } \\
\text { Loaiza (2011), pues } \\
\text { "la identidad se } \\
\text { construye al inte- } \\
\text { rior de las relacio- } \\
\text { nes... }\end{array}$ \\
\hline
\end{tabular}




\section{Resultados}

En la subescala de equilibrio entre derechos y responsabilidades, el 58,46 \% de los jóvenes puntuó medio y el 4,62 \% puntuó alto. Lo que se podría interpretar como un acatamiento moderado de la importancia de la ley, su cumplimiento y la incidencia en la colectividad, en el marco de la prevalencia de los derechos humanos. Así se presenta en la Figura 3.

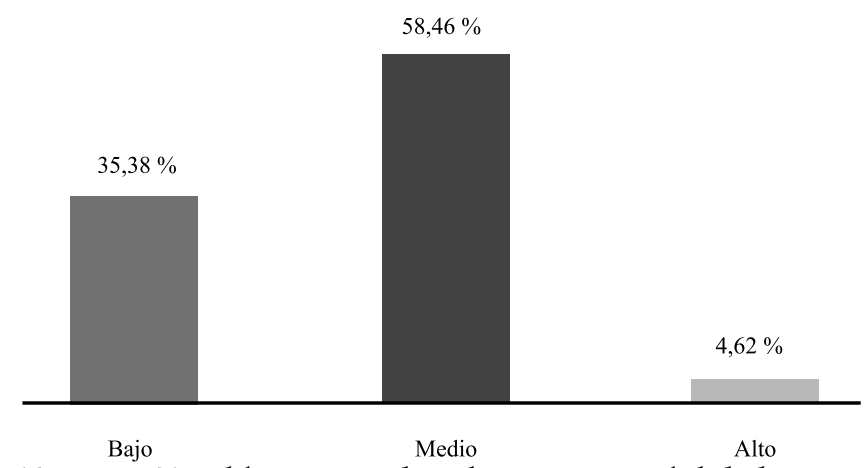

Figura 3. Equilibrio entre derechos y responsabilidades

De acuerdo con la información del grupo focal, cuando se habla del equilibrio entre derechos y responsabilidades, se hace alusión a dos dimensiones:

La primera se refiere al reconocimiento de la ley como factor preponderante para la orientación de la vida en común (Gómez \& Ruiz, 2011). Al respecto, los jóvenes exponen en su discurso la importancia de las normas y leyes sociales, tanto implícitas como explícitas, pero condicionan dicho reconocimiento a los beneficios propios. Esto se ilustra en los siguientes comentarios:

Cumplen simplemente por ellos mismos y ahi es donde empiezan a buscar solo sus derechos, en lugar de buscar una convivencia general, basada en cumplirle al otro para que el otro me cumpla; que mientras menos lo afecte a uno, uno menos interés le presta.
La segunda dimensión hace referencia a la exigibilidad a las instituciones, a los grupos sociales y a las personas, respecto al cumplimiento de las leyes y a la posibilidad de acceso a bienes y servicios (Gómez \& Ruiz, 2011). En el caso particular de estos jóvenes, muchas de sus manifestaciones se orientan hacia las inconsistencias que se presentan a la hora de equiparar las exigencias institucionales y las propias. A continuación se sintetiza un fragmento del grupo focal que permite ejemplificarlo:

(...) Con sus obligaciones sociales, porque muchas veces no concebimos la gran mayoría, la totalidad de nuestras obligaciones. Nosotros que acabamos de salir del bachillerato, en una escuela o incluso aquí en la universidad, los primeros semestres, siempre somos conscientes de lo que se supone que nos deben cumplir, somos conscientes, por ejemplo, en manuales de convivencia o en estas normas institucionales, de lo que se nos debe garantizar, pero cuando llega un alumno, al momento de cumplir su deber, se hace el que no es consciente o no es consciente de verdad o simplemente no tenía idea.

En general, los participantes consideran las leyes como restrictivas y excesivas en lo que concierne a las demandas de las instituciones. Además, suelen hacer referencia a la predominancia de sus derechos sobre sus responsabilidades.

En la subescala respeto a la diferencia, se encuentra una puntuación predominante en medio con el 46,15\%, que es equiparable a la puntuación alta con 47,69\% como se observa en la Figura 4. 


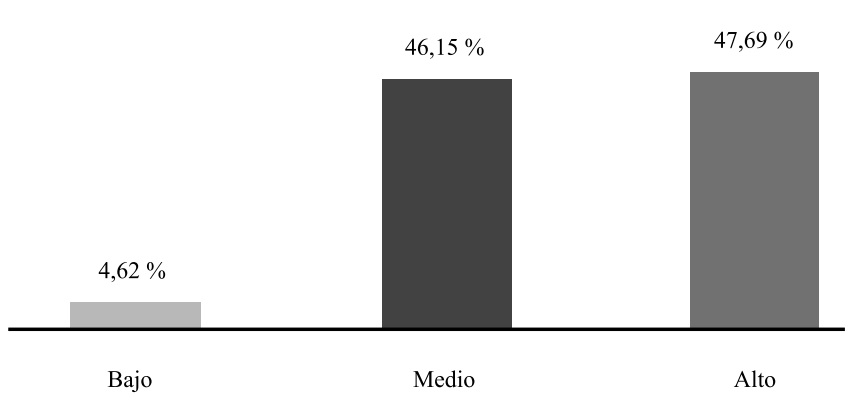

Figura 4. Respeto a la diferencia

Estos resultados parecieran indicar que los jóvenes respetan la diversidad cultural, racial, sexual y socioeconómica. No obstante, valdría la pena profundizar este aspecto en otros estudios, pues esto no coincide con algunas quejas de los docentes o con la percepción de otros estudiantes, que expresan exactamente lo contrario, es decir, un irrespeto por la pluralidad y una no valoración de las diferencias.

Las siguientes palabras de un participante ejemplifican la idea expuesta sobre el respeto hacia la diversidad:

A mí me encanta ver esa gente pelear, pues discutir, el término más adecuado es debatir, a mi me encanta verlos debatir. Entonces, en rumbas y, así, usted ve eso, este es rocketo, que este es metalo o este es reggaetonero, a este le gusta la bachata y baila bachata, este es vallenatero y así se ponen a debatir y a hablar, eso es muy bacano, porque en esos grupos es donde usted de verdad va cogiendo como cultura y va cogiendo relación con todo mundo, empiezas a socializar con todos, empiezas a tratar con todos.

Este asunto del respeto por las diferencias suele ser uno de los principales propósitos formativos de las instituciones educativas, pues se busca fomentar las actitudes ciudadanas que responden a los planteamientos del Ministerio de Educación Nacional (2004, p.8) en tanto estas:
Se enmarcan en la perspectiva de derechos y brindan herramientas básicas para que cada persona pueda respetar, defender y promover los derechos fundamentales, relacionándolos con las situaciones de la vida cotidiana en las que estos pueden ser vulnerados, tanto por las propias acciones, como por las acciones de otros.

Finalmente, en la subescala de las relaciones de inclusión, el puntaje más alto se establece en medio con el $53,85 \%$, luego se encuentra el nivel alto en $32,31 \%$ y posteriormente, el bajo con el 12,31 \%. Como se presenta en la Figura 5.

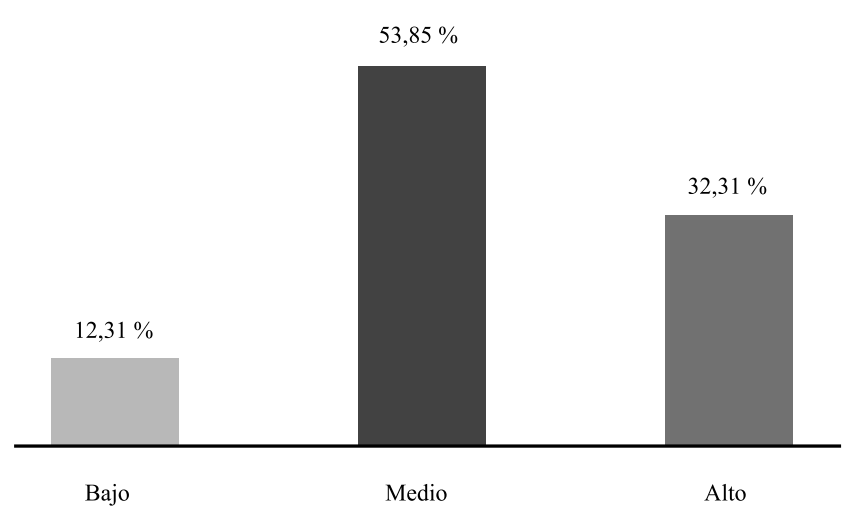

Figura 5. Relaciones de inclusión

Los estudiantes enuncian, insistentemente, la importancia de reconocer dentro de los grupos a las otras personas por sus diferencias y capacidades, asunto que les permite también nombrarse y reconocer lo propio. Ello coincide con el planteamiento de Arendt (1997) cuando hace referencia a que "en la medida que pluralidad significa distinción, es posible la revelación -en el medio público- de la individualidad de cada uno, de la identidad" (pp.20-21).

No obstante, algunos estudiantes reconocen que, pese a esta intencionalidad de ser incluyente, han naturalizado acciones cotidianas que excluyen y critican. En palabras de un joven: 
Yo creo que así es todo el mundo, cada cual con su gusto sexual, su religión, su forma de vestir, claro que uno muchas veces sí critica: "imirá esta cómo va vestida, cómo está peinada!", "imirá este man así!” pero lo normal, nada trasciende, como envidia...

\section{Discusión}

Es particular la tensión que se observa en los jóvenes en relación con el deber-ser y el ser-hacer. Pues, mientras el deber-ser se ve mediado por apreciaciones favorables acerca del respeto, la pluralidad, las responsabilidades, la igualdad de oportunidades, el cumplimiento social y la libre expresión, el ser-hacer, que se evidencia en sus narraciones, da cuenta de un nivel más experiencial y menos elaborado racionalmente, en las que describen situaciones que ejemplifican el predominio de los propios derechos, el uso de categorizaciones para incluir y excluir, la intolerancia y demás situaciones que parecieran ir en contravía de la intención positiva que plantean inicialmente. Esta clase de tensión también se evidencia en estudios anteriores, tales como los publicados por Arias y Pachón (2015) y Arias y Alvarado (2015).

La anterior reflexión resulta relevante para que en futuros estudios se indague acerca de la reciprocidad entre el reconocimiento de la importancia de la ley y las normas en la orientación de la vida en común, su acatamiento, la exigibilidad a instituciones, grupos sociales y personas para que las cumplan; y el acceso a los derechos constitucionalmente amparados.

Si bien, en cierto momento, los jóvenes manifiestan la apreciación por las diferencias individuales y sus producciones sociales, también expresan valoraciones desfavorables de sentidos y necesidades de otras perso- nas o comunidades como lo han dicho Gómez y Ruiz (2011) en su definición del respeto a la diferencia.

Es necesario entonces que las universidades, como escenarios de socialización política, propendan por la no discriminación y el autocontrol de los prejuicios, tal como lo plantean los estudios de Mendoza (2009) y Palacio (2007), respecto a la consideración y aceptación de la diversidad y a la valoración favorable de necesidades, sentidos y tradiciones de otras personas. Todo ello en la vía de lo que Navarini (2010) propone: "El pluralismo no solo acepta las nuevas culturas, sino que las incorpora a su acervo cultural que lo enriquece, elimina las desigualdades socio-étnicas, declara igualdad de oportunidades para todos y el valor de los derechos colectivos de las minorías" (p.4).

Por último, en próximas investigaciones se sugiere explorar asuntos como: igualdad de los seres humanos, dignidad de las personas, justicia en el trato, equidad; funcionamiento del grupo, roles de sus miembros, reglas y rituales de sus integrantes, procesos de interacción con otros "diferentes", construcción de lazos de confianza y solidaridad; participación en iniciativas en las que se defienden los intereses colectivos y se confronte la desigualdad social.

\section{Referencias}

Alvarado, S., Santacoloma, A. \& Loaiza, J. (2011). Programa Niños, Niñas y Jóvenes Constructores y Constructoras de Paz: una experiencia de acción desde la socialización y la subjetividad política. Manizales, Colombia: Centro de Estudios Avanzados en Niñez y Juventud alianza de la Universidad de Manizales y el CINDE. 
Alvarado, S., Arias A., Gómez, A. \& Pineda, N. (2013). Procesos de construcción social de la niñez en contextos de conflicto armado en el Eje Cafetero, Antioquia y Área Metropolitana de Bogotá: La paz, la reconciliación y la democracia desde la perspectiva de narrativas generativas de niños y niñas. (Ponencia del Ciclo de seminarios para la elaboración del Marco Teórico) Manizales, Colombia.

Arendt, H. (1993). La condición humana. Barcelona: Paidós.

Arendt, H. (1997). ¿Qué es la política? Barcelona: Paidós.

Arias, A., Arias, M., Jaramillo, C., Restrepo, F. \& Ruiz, D. (2013). Relaciones sociales entre jóvenes universitarios: una mirada desde las lógicas subjetivas. Estudio sobre discentes de segundo semestre de Psicología de la Institución Universitaria de Envigado y la Fundación Universitaria Luis Amigó. Recuperado de http://ridum. umanizales.edu.co:8080/xmlui/bitstream/ handle/6789/1125/Arias_Cardona_Ana_Maria_2009.pdf?sequence $=1$

Arias, A. \& Alvarado, S. (2015). Socialización en la universidad: equidad y aceptación de la diferencia entre jóvenes. Revista Lasallista de Investigación, 12(1), 1-45. Recuperado de http://repository.lasallista. edu.co/dspace/handle/10567/1356

Arias, A. \& Pachón, M. (2015). "Ética en jóvenes: norma, empatía y sentido de justicia en estudiantes de educación superior”. En Retos y realidades de la Psicología Educativa. Memorias del Congreso Nacional de Psicología Educativa (ASCOFAPSI) (p.184). Caldas: Editorial Lasallista.
Castillo, J. (2011). Adscripciones identitarias de jóvenes como horizonte de sentido de dinámicas conflictivas juveniles. En E. Vasco Montoya \& H. F. Ospina Serna (Eds.), Jóvenes, culturas y poderes (pp.145-160). Bogotá: Siglo del Hombre Editores.

CINDE \& Universidad de Manizales (2012). Paz Joven. Cartilla 3. Jóvenes Constructores de Paz. Estudio línea de base: evolución de las concepciones de las y los jóvenes constructores de paz frente a las categorías de justicia, inclusión y participación democrática. Manizales: CINDE- Universidad de Manizales. Recuperado de http://issuu.com/miguelladrong/docs/jcp_ cartilla3_impresi_n

García, B., González, S., Quiroz, A. \& Velásquez, A. (2002). Técnicas interactivas para la investigación social cualitativa. Medellín: Funlam-Fiuc.

Gómez, J. \& Ruiz, S. (2011). Ética, convivencia democrática y sensibilidad ciudadana. Manizales, Colombia: Centro de Estudios Avanzados en Niñez y Juventud.

Hernández, S., Fernández, C. \& Baptista, M. (2010). Metodología de la Investigación. México: McGraw-Hill/ Interamericana Editores, S.A. de C.V.

Martínez, J. (2011). Epistemología perspectiva postestructuralista (Módulo de Maestría en Desarrollo Educativo y Social). Universidad Pedagógica y CINDE, Bogotá, Colombia.

Mendoza, V. (2009). Un estudio sobre discriminación, el caso de la Escuela Primaria Alberto Correa. Maestría en Derechos Humanos y Democracia, FLACSO - Sede Académica de México. 
Ministerio de Educación Nacional (2004). Formar para la ciudadanía... jí es posible! Lo que necesitamos saber y saber hacer. Recuperado de http://www.mineducacion.gov.co/1621/articles-75768_archivo_pdf. $\mathrm{pdf}$

Mitjáns, A. (2013). Aprendizaje creativo, desafíos para la práctica pedagógica. Revista CS, (11), 311-341. Recuperado de http://www.scielo.org.co/pdf/recs/ n11/n11a11.pdf

Nateras, J. (2003). Procesos de socialización política y construcción del pensamiento social en infantes y jóvenes: La ruta de la sociocognición. Revista Polis: Investigación y Análisis Sociopolítico y Psicosocial, 2(003), 49-78.

Navarini, E. A. (2010). ¿Estamos preparados para "la pluralidad cultural"? Invenio, 13, 63-69. Recuperado de http://www.redalyc.org/articulo. oa? id $=87714453005$
Palacio, L. (2007). Exploración de las prácticas discriminatorias en la Institución Educativa América de la ciudad de Medellín, que inciden en la experiencia escolar del estudiantado afrocolombiano. (Tesis de maestría). Facultad de Educación Universidad de Antioquia.

Rodríguez, Z. \& Rodríguez, T. (2013). Socialidades y afectos: vida cotidiana, nuevas tecnologias y producciones mediáticas. Guadalajara, México: Universidad de Guadalajara Ciencias Sociales y Humanidades.

Secretaría de Educación Distrital de Santafé de Bogotá (2000). Estudio exploratorio "comprensión y sensibilidad ciudadana de los alumnos de grado del distrito capital". Recuperado de http://www.educacionbogota.edu.co/Centro_Documentacion/ anexos/anteriores_2004/estudioexploratorio.pdf 